Article

\title{
Scalable Green Infrastructure-The Case of Domestic Private Gardens in Vuores, Finland
}

\author{
Outi Tahvonen ${ }^{1,2}$ (D) \\ 1 School of Arts, Design and Architecture, Aalto University, Otakaari 1, FI-00076 Aalto, Finland; \\ outi.tahvonen@aalto.fi; Tel.: +358-50-5289850 \\ 2 Bioeconomy Research Unit, Häme University of Applied Sciences (HAMK), Lepaantie 129, \\ FI-14610 Lepaa, Finland
}

Received: 3 November 2018; Accepted: 30 November 2018; Published: 3 December 2018

check for updates

\begin{abstract}
The planning, implementation, and everyday use of the built environment interweave the green and grey components of urban fabric tightly together. Runoff from grey and impermeable surfaces causes stormwater that is managed in permeable surfaces that simultaneously act as habitats for vegetation. Green infrastructure (GI) is one of the concepts that is used to perceive, manage, and guide the components of urban green spaces. Furthermore, GI pays special attention to stormwater management and urban vegetation at several scales at the same time. This study concentrated on scalable GI in domestic private gardens. A set of garden designs in Vuores, Finland were analyzed and developed by Research by Design. The aim was to study how garden scale choices and designs can enhance GI at the block and neighbourhood scales to rethink design practices to better integrate water and vegetation throughout the scales. As a result, we propose a checklist for designers and urban planners that ensures vegetation-integrated stormwater management to enhance habitat diversity in block scale and possibility to use blocks of private plots for ecological networks. The prerequisite for garden designers is to be capable to balance between water, vegetation, and soil, and their processes and flows in detail the scale.
\end{abstract}

Keywords: garden design; scalable green infrastructure; systems thinking

\section{Introduction}

Ecosystem services support the well-being and health of urban residents. These benefits build up in a network of different kinds of urban green spaces that, together, can be considered an urban green infrastructure (GI). In other words, the urban fabric and its GI elements provide essential and nature-based benefits for residents as ecosystem services [1]. This approach includes a default definition of GI that comprises all shades of green in the urban context, including both public and private, and planned and unplanned urban vegetation, regardless of the land ownership or planned function. Therefore, GI and its shades of green penetrate all the land use categories.

However, the definition of GI is complex as the concept is applied to different purposes and scales. At its largest scale, the EU [2,3] perceives GI on a pan-European scale as a network joining the Natura 2000 areas that provide connections for fauna and appropriate patches for them to live in. At a smaller scale, detailed GI elements might concentrate on the techniques of green walls and roofs or best management practices in stormwater management [4]. Furthermore, discipline-specific definitions and uses make GI a multifaceted concept [5,6]. In the context of urban drainage management, GI is considered as networks of decentralized stormwater management practices, while landscape architects and urban ecologists use GI for describing networks of green spaces and landscape ecology [7]. According to Fletcher and others [5]: "A central tenet of green infrastructure is, of course, the use of 
vegetated systems to deliver desired ecosystem services". These approaches stress the connection of water and vegetation within GI.

While the definitions of the concept of GI depend on the used scale [8] and discipline [5], certain common attributes define its nature. GI is multifunctional, scalable, connective, and resilient $[8,9]$. Multifunctionality reflects the ecological, technical, and sociocultural functions that exist simultaneously in one space, such as buffering of climatic extremes, biomass productions, provision of habitats and biodiversity, species movement routes or opportunities for social interaction and nature experience. This division of multifunctionality to three main components, ecological, economic and sociocultural functions, relate the whole concept to sustainable development and its triple bottom line [10,11].

Urban planning deals with these attributes in all land use categories, including commercial, industrial, residential, and traffic areas, as opposed to just parks and conservation areas. While the share of the green component of the total surface of high-density areas is limited on its own, it can be integrated into buildings and constructions as well as green roofs and walls [12]. In addition, different land uses generate different concentrations of pollution in runoff, so considering multiple land uses simultaneously might complicate the design process [13]. From the perspective of GI, low density housing (LDH) is one of the most diverse land use categories. The GI of LDH comprises small areas managed by owners, and the needs and habits of gardens vary as time passes. These separate, small areas form a coherent gardenscape [14].

$\mathrm{LDH}$ and the garden matrix formed in the area cover a significant share of an urban area. According to Loram and others [15], the gardens of low density housing cover $22 \%$ of the surface area of examined towns and cities in the UK, while according to Mathieu and others [16], these constitute $36 \%$ of a town in New Zealand. The share of the gardens in LDH areas of total urban green spaces has been found to amount to $35-47 \%$ [15] or even over $50 \%$ [16]. It is assumed that the share of the garden area of LDH will continue to increase because of ongoing urbanization [17].

The characteristics of domestic gardens are determined based on plot sizes and the layout of buildings and parking spaces within the plot, as impervious surfaces prevent vegetation from growing. The ratio between impervious and pervious surfaces on a plot depends on the density, period of construction, and building types in the area [18]. The layout of this grey and impermeable proportion of a plot defines both the accumulation of stormwater and areas that may infiltrate and allow ground soil-based growth of vegetation. Furthermore, water and vegetation are interwoven through soil or growing media. The characteristics of soil determine both the hydraulic conductivity of water, the water storage, and the capillary action to bring water up the roots of vegetation, but also nutrient and water provision for the needs of vegetation [8]. Few studies have described the nature and extent of impermeable and permeable surfaces at a garden scale. Lawn is the most commonly used surface, covering $55-60 \%$ of the surface area $[16,19]$. The prevalence of pavement and asphalt has also been investigated, and a 13\% increase was noted in their proportions in Leeds, UK over the previous 30 years [20].

Therefore, areas with LDH constitute a diverse gardenscape that serves as part of the urban ecological network and provides the same ecosystem services as other urban green spaces. It can therefore improve the air quality and microclimate as well as human health and wellbeing, contribute to stormwater management, and play a part in flood control [21].

This study examines how garden design can be used to improve the role of the gardens of low density housing as part of the GI and the effects of this on the block and neighbourhood scales. The main driver in this study is to explore the opportunities for developing GI from a perspective of garden design. The research data is based on the standard practices of the design process of the Research by Design method as well as choices made in an area with LDH in Finland. The research questions are as follows: How can garden designs that combine vegetation and stormwater management enhance GI at the garden scale? How is this improved design practice on the scale of plots reflected at the scales of the entire block and neighbourhood? 


\section{Theoretical Background: Planning and Design of Scalable Stormwater and Vegetation Systems}

In the context of GI planning and design, scalability can be perceived at both the scales used in the design and the links between these as well as at a temporal scale. In the present paper, scalability primarily refers to spatial links between different scales.

\subsection{Garden Scale}

Plot-specific garden design brings together the needs of garden users and the conditions provided by a plot. In this context, the conditions consist of the layout formed by the placement of buildings in relation to the streets and the arrangements for entrances and car parking on the plot. This layout determines the need for passageways and, as a result, often also includes the extent and placement of impervious surfaces on the plot. In turn, the actual vegetation on the plot will be located in the areas that are free from impervious surfaces, although some vegetation may also be planted between the hard surfaces for purposes such as screening the yard from outsiders or improving the comfort of entryways.

From a garden design perspective, vegetation plays a number of different roles. While vegetation is one of the key elements for spatial design, it differs from other design elements, such as terrain shapes or structures, as it is living and changes constantly. In addition to creating spatial features, plants can serve as space dividers, frames to a view, or ornaments; produce biodiversity and a habitat for fauna as planting systems; and improve the microclimate; or provide screening to residential spaces. In addition to these goals, the selection of plants is determined by availability, factors related to growth potential at the design site, and hardiness [22,23].

Vegetation and water are the most fundamental and central elements of GI [8]. In the context of scalable GI, the smallest unit of vegetation is an individual plant, whose viability is based on the availability of water and nutrients at the growth site. If a growth site does not provide the conditions necessary for a plant to grow, these must be improved by means such as irrigation or fertilizing, or the plant's growth will be stunted or the plant may die [24]. However, the water centric approach to this small scale GI element concentrates on plants capability to minimize urban runoff. Ossola and others [25] studied how an increase in habitat complexity minimizes the urban runoff. They found three main factors: an increase in canopy density and volume, preservation of surface litter, and maintenance of the soil macropore structure. These factors apply to the plant scale.

When examining GI, particularly as a tool combining stormwater management and vegetation, two main approaches can be observed: vegetation integrated best management practices and tools stressing the extent of different surfaces. The Green Factor (GF) or similar tools give scores at the design stage to different surfaces and their proportions of designed area in order to improve the capacity of plots to generate urban green spaces. For example, the volume of growing media under a surface material can be a GF scoring criterion. While this is not a stormwater structure as such, it describes the water infiltration and retention potential under the surface materials [26,27]. However, stormwater management is more commonly based on sustainable urban drainage systems (SuDSs) that emulate the processes of the natural water cycle $[28,29]$. SuDSs provide a more or less standard toolbox of constructions with relatively well-known functions in order to manage the quantity or quality of stormwater. However, there are several approaches to categorize SuDS, and for instance Charlesworth and others [30] categorized SuDS into five device groupings (adapted in Figure 1). SuDS-based design has recently highlighted an aim of combining stormwater management with amenities and puts more emphasis on biodiversity [31]. This combines SuDS with urban vegetation. However, it is notable that not all SuDSs contain vegetation or rely on the processes of plant growth in stormwater management (Figure 1). This observation was supported by Wootton-Beard and others [32] as they claimed that urban design and planning require biology as well as engineering. 


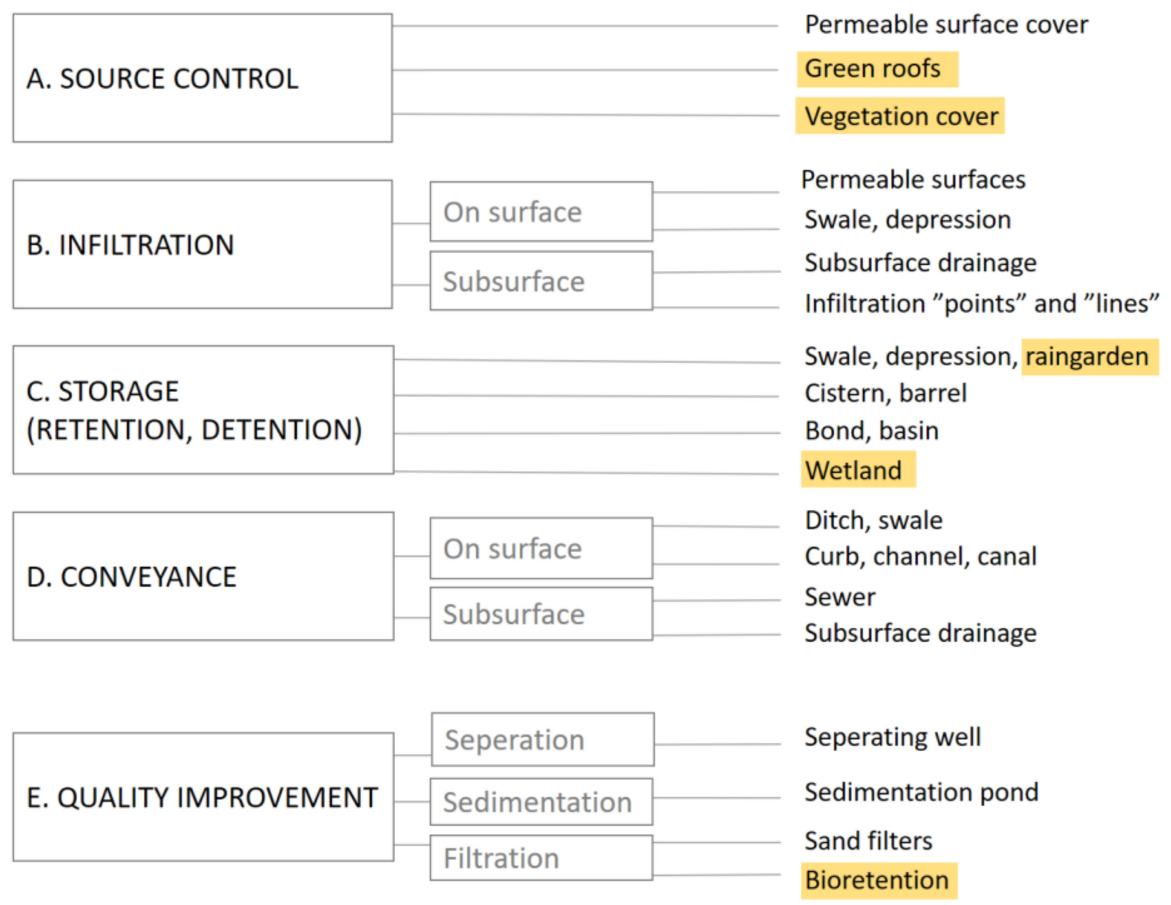

Figure 1. Sustainable urban drainage systems (SuDSs) devise grouping (in left) describes the general functions of stormwater management practices. These functions emulate the processes of the natural water cycle. Technical details of individual SuDS (in right) and their primary function define how they belong to different SuDS devise grouping. SuDS that contain pivotal and functional roles of vegetation are marked in yellow. (SuDS devise grouping adapted from [30], SuDS examples adapted from local practices described in [33]).

\subsection{Scaling $U p$}

In the water system, in contrast with separate SuDSs, stormwater management may also be designed as treatment trains. In these trains, a single SuDS is not assumed to solve the challenges concerning quantity, quality, or amenity, but instead, is perceived as an individual part of a larger solution [31]. Designing the trains also allows a better perspective of the different management practices in the whole design area to be obtained. As a result, the stormwater management of the upper parts of a watershed can be implemented with methods that reduce the volume of generated stormwater, while the approaches used at the lower parts of the system can be expected to level flood peaks and flows. However, the design of this treatment train must be viewed separately from flood passage design, as the treatment chain aims to solve the challenge of stormwater management in several consecutive sections. Therefore, an individual SuDS is not required to provide the most efficient solution possible, but rather, the tasks of stormwater management can be divided between the different parts of the treatment train.

Plot-scale treatment trains consist a set of SuDS placed in sequential order along the gradient. If it is not allowed to provide runoff or drained water from plots, then the treatment train consists only the SuDS inside the plot. However, the approach of treatment train applies also to up scaled water systems in blocks and neighbourhoods. At these scales the main focus is on different purposes and functions, or SuDS groupings according to Charleswoth [30], for the parts of the entire water management system.

When scaling up to watersheds or sub-watersheds, studies have been shown that the percentage of impervious surface area predicts the condition of the receiving water body [34]. With a higher proportion of impervious surfaces in the watershed, more problems are caused in receiving waterbodies by contaminants, erosion, and changes to temperature and flow rate [35]. Indeed, in urban planning, the Total Impervious Area (TIA) has been used as one of the indicators for the ecological impacts of 
planned construction and for estimation of pollutant loads from different land use categories [36]. Nonetheless, there are some weaknesses associated with the use of TIA in studies, which Brabec and others [34] have identified to include variation and a lack of clarity over which part of an impervious surface is directly connected to drainage system. As a result, the concept of the Effective Impervious Area (EIA) has been introduced alongside TIA. EIA only includes the impervious surfaces that are directly hydraulically connected to the drainage system. The concept does not include those impervious areas whose surface runoff is directed to areas covered with vegetation. However, the EIA has not been established as a standard indicator for planning and related steering, and the studies using the concept have mainly used it to describe existing neighbourhoods, focusing on plot-specific observations and aerial photographs [34,37].

In a plant system, the next scale up from an individual plant is a group of plants or a plant community. This may be a monocultural mass planting in a built environment or a habitat comprising various species in several overlapping layers. Recently multi-layer vegetation has been noted to be a key factor in supporting biodiversity [38,39].

The planning of urban ecological networks involves the identification of urban green spaces as patches, corridors, and matrices. Traditionally, the backbone for these networks has consisted of public green areas, such as parks, green spaces around streets, protective green zones, and conserved areas. In recent discussions, however, attention has been focused on the matrix between these patches and corridors, the exact part of GI that this study concerns [14]. When considering the urban green as a whole on a city scale, it is important to note that it plays a variety of roles in addition to the ecological one. These roles include curbing the urban heat island phenomenon, providing an environment for commuting and recreation, and fostering the equal availability of so-called green services to different residential areas [40].

\section{Materials and Methods}

This study explored the garden scale choices by first identifying a set of state-of-the-art garden designs and then developing and re-designing these garden designs to better serve GI by scaling them up to the block and neighbourhood scales. This development at the garden scale was carried out as an iterative design process during re-designing and upscaling.

The method followed the Research by Design $(\mathrm{RbD})$ method, which explores practical design processes through several iterative and scientific reflective cycles [41], and systematically combines research inquiry and design thinking [42]. $\mathrm{RbD}$, as one of the qualitative methods, aims not to gather numerical data, but focuses on the human element on how vegetation and stormwater management could be integrated during the design process in scales of gardens. According to Glanville [43], $\mathrm{RbD}$ combines both the research object and the means of carrying out the study. Here, the object was a set of garden designs that simultaneously serve as the means of carrying out the role of garden design in the context of GI in LDH.

This study applied the idea of grounded theory (GT) for analyzing the data produced in the design process of $\mathrm{RbD}$. GT provides a general and non-discipline specific methodology that was used to analyze the iterative part of this study to reveal the conceptual context and linkages of vegetation-integrated stormwater management. Furthermore, GT allows a wide range of data collection methods.

On a city scale, urban green spaces, biodiversity, and green infrastructure are often studied by remote sensing or from satellite images that show the existing situation. In this study, garden designs were used to present a view of how things ought to be "instead of how things [actually] are" in accordance with Simon's [44] description of the difference between natural science and design.

\subsection{The Context}

The data of this study comprised 24 garden designs from the Vuores neighbourhood in Tampere, Finland, which served as the location for a national housing fair in 2013 (Figure 2). The gardens 
were designed and constructed simultaneously in the same area, and they followed the same design guidelines. The gardens can be considered to reflect the views of professional designers on the practical application of the main theme of the fair, sustainable stormwater management. The gardens in the fair area also play a significant role in creating an idea of a functional and ecological garden that meets today's standards among detached house constructors, as Finland's national housing fair is annually visited by nearly 100,000 people. According to surveys, visitors have reported getting ideas for their garden as one of the main reasons for visiting the fair [45].
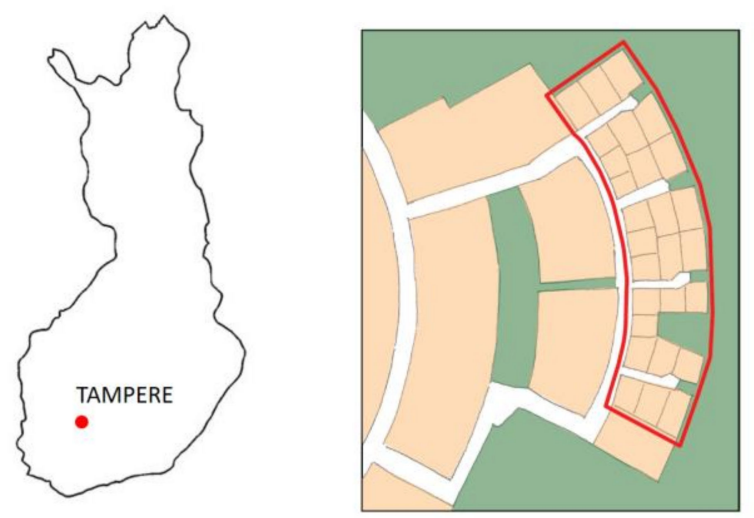

Figure 2. Vuores is a new development south of Tampere, Finland. This study concentrated on private domestic gardens and their garden designs in this area (marked in red). These plots are located between a large park/urban forest and multi-storey buildings.

\subsection{The Process}

This study examined designs and designing. The practical design work involved finding a balance between a number of factors (presented in Section 2.1), of which stormwater management or creating potential for biodiversity are only two examples.

First, the analysis of a set of existing garden designs concentrated on how the elements of stormwater management and vegetation existed and situated, and how they were integrated into the designs. Furthermore, the intended functions of these elements were mapped as it was the backbone of conventional design process. Then, in the second phase the garden designs were re-designed to improve water and vegetation integration, meanwhile the original layout and functions in plot scale were respected. These improved designs were further developed by considering their input first to block and then to neighbourhood scales. This scaling up and down provides an iterative design process that was repeated once for each plot. It was originally developed as garden scale designs, however, the outputs of these upper scales are also reported in this study (Figure 3).

In this study, $\mathrm{RbD}$ was used to provide several re-designing loops to ensure and develop designers approach to integrate vegetation with water. These loops were analyzed by coding and categorizing designs, that follows the applied methods in grounded theory (GT). Open coding was used to identify, name, and describe the development of designs. In coding we mapped all the main changes in the set of improved designs, meaning that the information in drawings was switched to written form. There were 2-8 coded changes or observations per design. These codes were then organized under categories describing more general themes, and they are presented in the section Vuores but also in the theory section. Our findings present inductively produced knowledge of designers' possibilities to integrate vegetation and water in plot scale. The theory concerning this finding is presented in the Section 2, but the core category, soil-vegetation-water system, is presented in Section 5. 


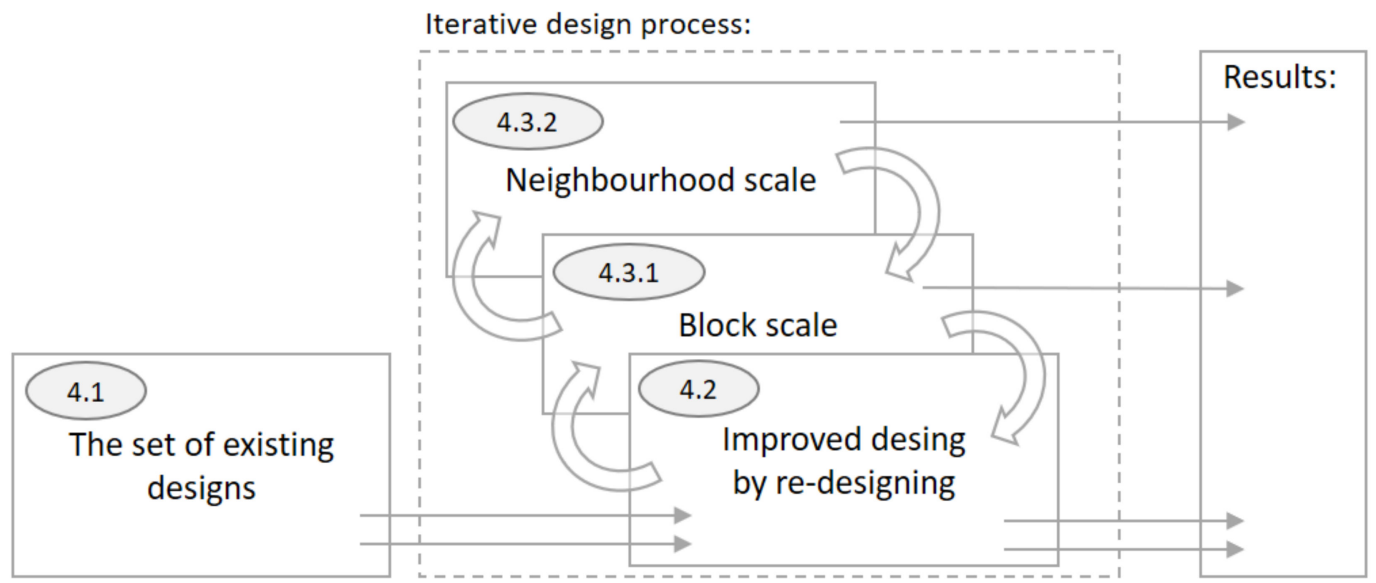

Figure 3. The used method, Research by Design ( $\mathrm{RbD})$, focused on the iterative process of re-designing the set of garden designs. This developed the garden scale designs by scaling up to the block and neighbourhood levels. The results of this study were based on the outcome of the garden scale development process, but findings are also presented on the block and neighbourhood scales. Numbers in the figure refer to section numbering in this paper.

The data included all available 24 garden designs in Vuores marked in red in Figure 2. This data seemed to be wide enough as the same categories started to appear in analysis and therefore the saturation of this data was achieved.

Although the research material was based on extremely practice-oriented work and its results, we consider this study to be an important addition to scientific research where the primary focus related to LDH has previously been on examining existing areas or investigating a single functional aspect. As noted by Harrison-Atlas and others [46], carefully defined studies that bridge the gap between science and practice are needed in the context of sustainability.

\section{Results}

Whether consisting of carefully prepared design documents or a series of separate choices made by an owner, the solutions related to the vegetation and stormwater management on a garden scale are defined in a garden design. In this section, we first analyze garden designs prepared by professional designers, and subsequently improve the integration of water and vegetation by re-designing these on plot, block, and neighbourhood scales.

\subsection{Analysis of a Set of Existing Garden Designs}

In garden design, decisions are made on the form and style of the overall layout, the location and sizing of different features, and the use of space dividers to separate different parts of the garden. The space may be divided into spaces using structures, planting areas, terrestrial elevation, or a variation in surface materials. While all of these elements were seen in the gardens in the Vuores housing fair site, the proportion of sealed surface was higher than in typical gardens. Paved pathways were used to support visitor movement during rainy days at the fair. In general, the design area was made for the everyday use of families. The Finnish housing fair concept did not adopt the show garden style with diverse and ornate plantings that is common in countries such as the United Kingdom.

Our analysis of the garden designs revealed, in this case, the difficulty of combining stormwater management with vegetation. In Vuores, plot sizes ranged between 454 and $935 \mathrm{~m}^{2}$, and the floor area ratio was 0.35 . These numbers depict the relatively high density of LDH in the Finnish developments. While opportunities for stormwater management have been provided in master planning, the garden scale solutions have primarily handled vegetation and stormwater management as distinct systems. For instance, gutters and water retention may even isolate vegetation from the SuDS. Moreover, 
narrow planting strips located in the middle of delineated paving may end up relying fully on irrigation water. At the time of the fair, stormwater management had only recently been introduced to the public discussion in Finland, and the main focus in the fair area was on presenting individual and, at times, rather isolated solutions and products. Stormwater management methods integrated in vegetation mostly consisted of rain gardens and the infiltration of small amounts of water at the edges of lawns [47].

In this set of designs, vegetation served five different main purposes. First, plants were used for property boundaries as both cut hedgerows and freely growing plant masses. Vegetation was also used as an element for separating the spaces and functions within the plot, in which case the elements usually consisted of shrubs or perennials. Some of the vegetation also appeared to serve an ornamental purpose. In some of the gardens, plants also contributed to food production in green houses and vegetable gardens, a task that relies on annual plants and their intensive growth during a single growing season. Lawns were the fifth use of vegetation; they were used to determine the shape of spaces, even if not otherwise demarcating the area. None of the garden designs retained the original vegetation of the plot. Figure 4 a presents a schematic drawing of the types of vegetation and their locations and describes the overall arrangements of the gardens in the fair area.

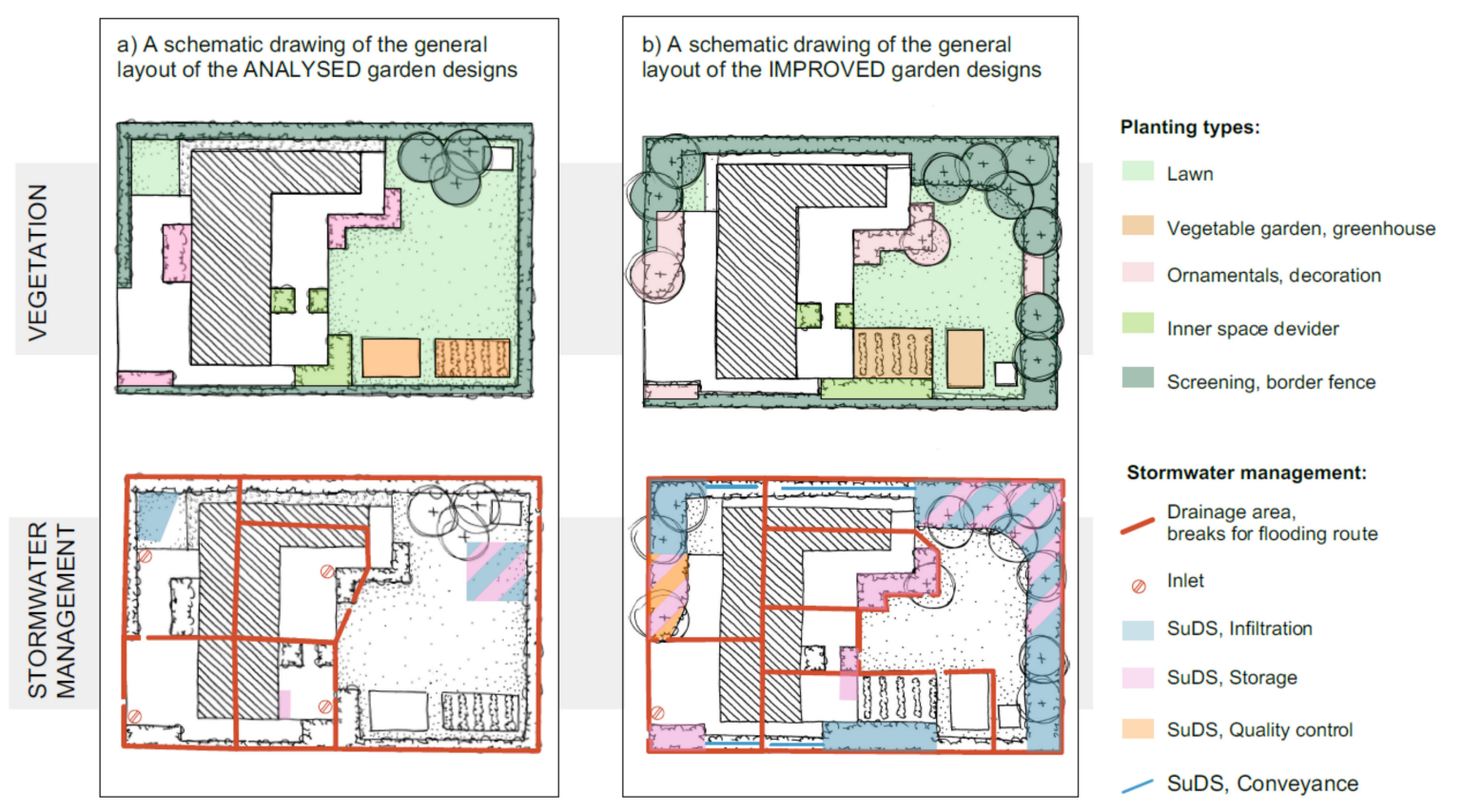

Figure 4. (a) A schematic drawing describing the arrangement of plotS, the volumes and locations of different planting types, and stormwater management; (b) The same schematic design after improving the integration of vegetation into stormwater management shows the change in vegetation's roles.

\subsection{Improved Garden Designs}

The following step included examining the opportunities for better integration of stormwater and vegetation when redesigning the gardens. The starting point was the general principles of the original design, and the aim was to retain the functions, styles, form, and space dividers used in the design (Figure 4b).

The first step in the design process was to refine the size of the planting areas according to their functional type. This led to enlarged planting areas which played a key role in property boundaries. Similarly, the inner space dividers located in the middle of the hardscapes were enlarged to better provide the required soil volume to improve both the infiltration capacity and the storage of water for the use of vegetation. Ornamental plantings also partly served as space dividers on the plots, especially when combined to raise beds or other constructions. For these, the utilisation of runoff must 
be more carefully considered as a raised planter may be totally separated from the soil by structures or capillary gaps. In practice, this first step means ensuring there is sufficient volume of growing media for water retention and plant growth.

The second step appeared to concentrate on the re-evaluation of the placement of the different planting types in relation to the runoff sources. Planting types with high water demand were located close to the downspouts and outer edges of impermeable surfaces to better benefit the available runoff. The designs revealed that ornamental plantings, in particular, if not growing in raised beds, and inner space dividers could benefit stormwater integrated growing conditions. For residents, these planting types are, in any case, part of the essential vegetation for gardening as a hobby. Of all planting types, greenhouses and vegetable gardens require the most water. Paradoxically, these types were usually placed at the most remote part of the plot, at the back of the yard, in the original designs. However, these plantings require a consistent supply of water to yield crops, and therefore, water storage in containers or barrels is needed.

The third step of the re-design process appeared to consist of defining a stormwater treatment train. The re-design process aimed to integrate the planting types and their water demands into the treatment trains. The single SuDSs in the original designs were transformed into multi-phase treatment trains. The aforementioned utilisation of the ornamental plantings or inner space dividers emerged as a central development. However, a challenge arose in this context due to the local recommendations which state that infiltration should occur at a distance of at least $3 \mathrm{~m}$, and preferably $6 \mathrm{~m}$ from a building. Moreover, in Finland, ground frost sheets are used next to buildings at a 1.5-m distance from the wall base for ground frost insulation purposes, which sets limits for planting vegetation on the sides of buildings.

The re-design process revealed that the treatment train seems to form a linear set of separate SuDSs. This happens when designing starts solely with stormwater management. However, when designing is integrated with vegetation, it also expressly concerns extensive surfaces, such as large planting areas or entire lawns. In fact, the supply of water to these areas can be managed as extensive surface runoff that evenly crosses pavement borders. In an LDH plot, paved surface areas are primarily so small that no problematic erosion forms at the lawn borders. The situation may be different, however, if the water is initially directed to a certain point using kerbstones. A similar difference in approaches is also apparent in planning the management of water from a downspout (a spot-like release) or from paving used in the garden (as a wide front runoff). The utilisation of surfaces as part of the treatment train as water resources for vegetation was one of the key changes made to the original designs. This means that impervious surfaces should be perceived as water-generating areas and the vegetation surface should be perceived as an equal water-using area, even if it is not named as a method of SuDS. Therefore, all vegetation covered surfaces should be perceived as part of the stormwater management train, in which the slope and the material of the surface determine its effectiveness in stormwater management.

According to the examined garden designs, the placement of infiltrating SuDSs on the plots was based on, firstly, the avoidance of non-permitted infiltration areas and, secondly, the sizing of SuDSs. Moreover, in cold climates, snow, snow piling sites, and melted water on top of frozen ground require careful placement and sizing.

The practices of stormwater management including infiltration always require water flows to be perceived as both surface runoff and surface layer runoff. An examination of the water movement to the foundations of buildings and structures in relation to the drainage and frost insulation required revealed that any planting areas placed at the centres of paved areas must be carefully designed. This is due to the fact that sub-surface drainage systems intended to keep the base of a wall or pavement dry can easily be overburdened by the irrigation water used in an adjacent planting area. Another problem of subsurface drainage systems is that they are usually maintenance-intensive and prone to clogging issues [48]. Similarly, construction layers with big grain size cause the surrounding growing media to 
dry, in which case the volume of the growing media must be increased. In practice, this results in the planting areas in the middle of pavements and narrow stripes expanding.

As a whole, the integration of stormwater and vegetation in LDH plots appears to work well due to the relatively low water volumes. If a plot receives runoff outside its borders or if there is an uncommonly large impervious area, the potential for plot-specific stormwater management is naturally reduced. The design process that integrates vegetation with stormwater management needs to start with form and functions like any design process. Planting types are determined by the actual functions and spaces of a garden, and then plant water availability is ensured by appropriate runoff routes, infiltration, and storage. This vegetation integrated stormwater design creates treatment trains between different planting types and ensures that stormwater does not cause problems to constructions, garden use, or, if ponding occurs for a considerably long time, vegetation. It is of utmost importance to also include vegetated areas, such as mass plantings and lawns, instead of merely focusing on band-like substitutes for ditches.

\subsection{Scaling $U p$}

The plot scale designs were improved in stages. This gradual and iterative work progressed initially at the scale of blocks and subsequently, included the entire low density housing (LDH) area. This upscaling was used to examine the significance of plot-specific choices at higher scales.

\subsubsection{Blocks}

At the scale of blocks, even more emphasis is put on the placement of buildings and parking spaces than at the plot level. This is due to the fact that the building masses and their elevations form a block-specific micro watershed dividing front and back yards from each other. At the same time, this placement, combined with roof shapes, determines the volume of water accumulated from roofs to the part of the plot where the water must be managed. This also determines the amount of space available for stormwater management, and therefore also the set of suitable SuDSs.

At the block scale, re-designing revealed an opportunity for a so-called shared growing media volume which emerges at the borders of plots, as opposite planting areas are adjacent to each other. This is noteworthy, as growing media volume was one of the challenges observed at the plot scale. Utilising shared growing media volume naturally requires the planting areas to be located at the same section of the plot border, and there should also be no changes expected in the neighbours' plot use.

The block scale can also be used when working on large planting areas where plant communities (man-made habitats) can be developed. These habitats can emerge at the centres of blocks when water management and vegetation are located in the same area. In the blocks examined in this study, a stormwater flood route based on the locations of building masses and their elevations and a related vegetation area had already been created at the centre of the block at the planning stage. The design at the block level also included the use of this vegetation area for safe infiltration at a sufficient distance from buildings, and a possibility, to provide a harmonious forest stand and a resulting increase in crown closure on the block. This could allow the creation of larger vegetation-covered patches with multi-layer vegetation to support biodiversity on the block scale.

In addition to the slightly obvious definition for the multi-layer, eutrophic vegetation areas, this idea for habitat construction includes the examination of other built environment habitat types (Figure 5). Second, walkways and the sides of buildings, which are kept dry to ensure accessibility or healthy structures, create a dry growth environment on, and at the immediate vicinity of, these surfaces. As a result, the placement of buildings and walkways may form dry habitats across the borders of individual plots at the block level. At the same time, these areas between buildings tend to be the ones where inhabitants wish to use vegetation to create protective screening between plots and to the street. This produces third habitat type at the block level, where vegetation is planted on naturally dry spots in the middle of hard surfaces. The growth of sufficient media to retain water and nutrients must be ensured for this habitat type, and an adequate water supply must be provided for the planted 
vegetation. The fourth habitat type at the block level is comprised of vegetable patches that require regular moisture. While some plots may not include these, there are good grounds for placing these at the borders of plots adjacent to neighbours' patches to ensure the necessary humidity conditions and equal levels of light.

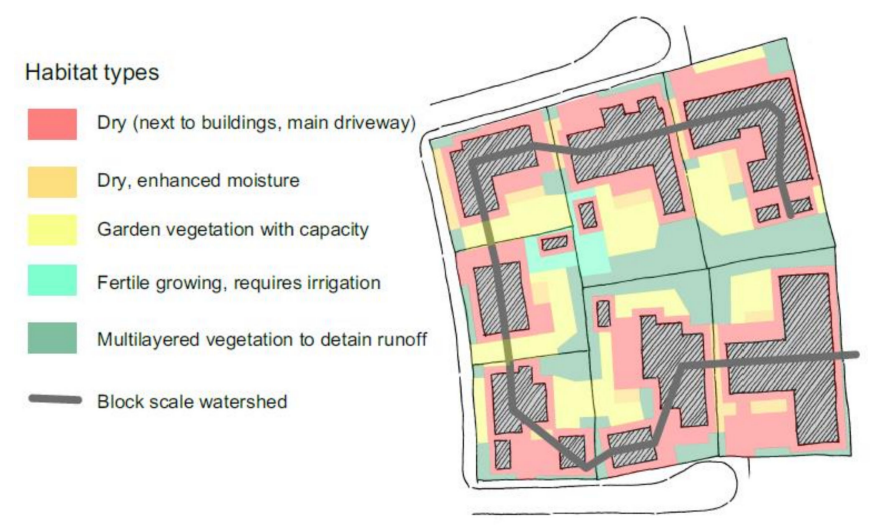

Figure 5. Adjacent plots formed five different habitat types for blocks. The moisture conditions in these habitats are based on the areas of construction layers and sub-surface drainage with irrigation dependent vegetation, with those with a high infiltration capacity with multi-layered vegetation in the centre of the block.

The fifth habitat type was open surfaces with low levels of vegetation-typically lawns and the planting areas commonly placed at lawn borders. At the block level, these lawnscapes are located in front of buildings and, particularly, next to patios. Even though lawns are rarely perceived as a part of stormwater management, the block-level examination revealed that they are located between water-producing hard surfaces and the eutrophic biotypes that need the most water, and they must therefore be perceived as part of the treatment trains.

\subsubsection{Neighbourhoods}

In addition to blocks consisting of plots, the GI of neighbourhoods comprises public parks and street networks. On the neighbourhood scale, vegetation is divided into trees planted alongside streets in a band-like formation or areas of plants around streets and vegetation patches in parks. Vegetation plays similar roles in parks as on the plots. However, in this area, vegetation is primarily perceived as forests and groves, meadows and other open spaces, or gardenesque sections of parks.

The layout of a neighbourhood divides the GI into the private green areas of blocks and the public green areas of parks and streets. Therefore, the layout of a neighbourhood defines what kind of GI continuum is created for people's physical activities and as a habitat for fauna. While urban planning is primarily concerned with the construction of the biophysical environment, functional connections, such as streams of water and nutrients, also affect the design of the GI, particularly at the neighbourhood scale.

Neighbourhood scale GI planning can utilise wooded patches growing in blocks as a kind of stepping stone passing through the area. This allows the lush parts of blocks to supplement broken ecological connections, support the landscape ecology patches located nearby, or create new connections. The shared growing media volumes of blocks may also be connected to park zones, thus providing possibilities for connections to the micro-organisms in the soil.

On this scale, watershed divides emerge as a result of the building masses in blocks and the elevations and inclinations of the street system. As such, street areas and kerbs serve as flood paths. However, water from the streets will primarily flow to the sewer system, as the ratio between pervious and impervious surfaces does not primarily favour SuDSs. The potential for urban green areas in stormwater management is determined by the scaling of the cross-section of the street area in urban 
planning. If the dimensions of streets allow it, a green street can provide a band-like connection through the street network in the form of trees planted alongside the street. On the streets along which plots are located, the stormwater management approaches are focused on water infiltration and increasing the delay in water flow (Figure 6).
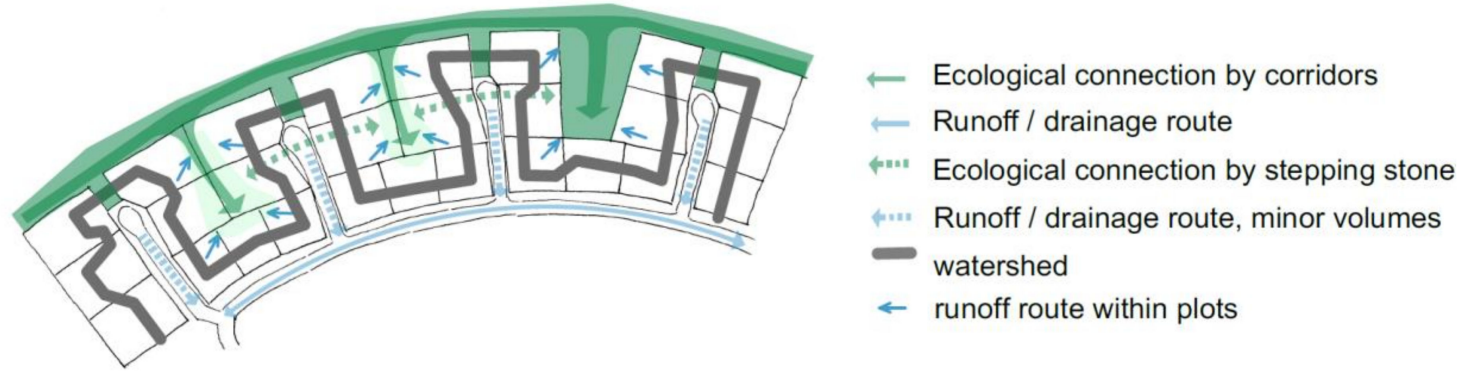

Figure 6. Neighbourhood scale defined flooding routes and vegetation patterns that may support the ecological network.

\section{Discussion}

The purpose of this study was to describe how the GI of an area with LDH can be developed by first, improving the garden scale designs to better integrate water and vegetation and second, scaling up from plot scale garden designs to habitats at the block scale and ecological networks at the neighbourhood scale. This bottom-up, decentralized approach follows Keeley's [49] claim about the need to develop the practices of GI planning. The results indicate that while combining stormwater management with the planting types typically used in garden design appears to work, this requires the recognition of their level of water demand. On the block scale, vegetation should make use of shared growing media between neighbours and rely the diversity of habitats that form from block scale arrangements of green and gray components. This block scale arrangement may form cohesive vegetation by shared soil volumes and smooth stormwater infiltration in the lowest corner. These habitats with multi-layer vegetation are determined in design at the scale of the entire neighbourhood, which includes the creation of a network of ecological corridors, patches, and matrices. Nonetheless, all types of habitats, from dry to water-absorbing plantings, should be appreciated in order to avoid inappropriate infiltration in areas that are drained with the means of constructions and their foundations.

Vegetation integrated stormwater management and, especially, the use of multi-layered vegetation, generates two simultaneous benefits. First, multi-layered vegetation provides a design element for defining a space and its edges. For this purpose, it is essential to have multi-layered vegetation. This space forming role of SuDSs is not too often discussed, and the guidelines seem to concentrate mainly on the nutrient removal capacity of vegetation, water tolerance, or presence of native species. Second, multi-layered vegetation has recently been mentioned in several studies as the key component of biodiversity $[38,39,50]$. Furthermore, this potential for biodiversity is proposed to especially rely on residential areas $[39,51]$. Figure 7 sums up our proposal for a designer's checklist to work with scalable GI that starts on plot scale designs.

Based on this study, there appears to be room for development in the design practices if the aim is to improve the GI of LDH. Vegetation integrated stormwater management requires constant assessment of the amount of water needed by vegetation and its capacity to tolerate ponding. However, this integration cannot be carried out without consideration of the surrounding environment and its moisture conditions in the foundations of constructions. Therefore, vegetation integrated stormwater management is based on stormwater management whereby treatment trains through vegetation-covered areas allow water to be infiltrated and stored in the growing media, thus allowing runoff be conducted slowly and as a wide front across planting areas and lawns in addition to other SuDSs. The main difference with this approach and traditional SuDS descriptions is that water 
is perceived as a resource that is necessary for plant growth and, additionally, the flows of water are perceived as surface layer runoff instead of only as surface runoff. This approach requires the understanding of both water and vegetation as well as the flows formed by the soil that conveys these.

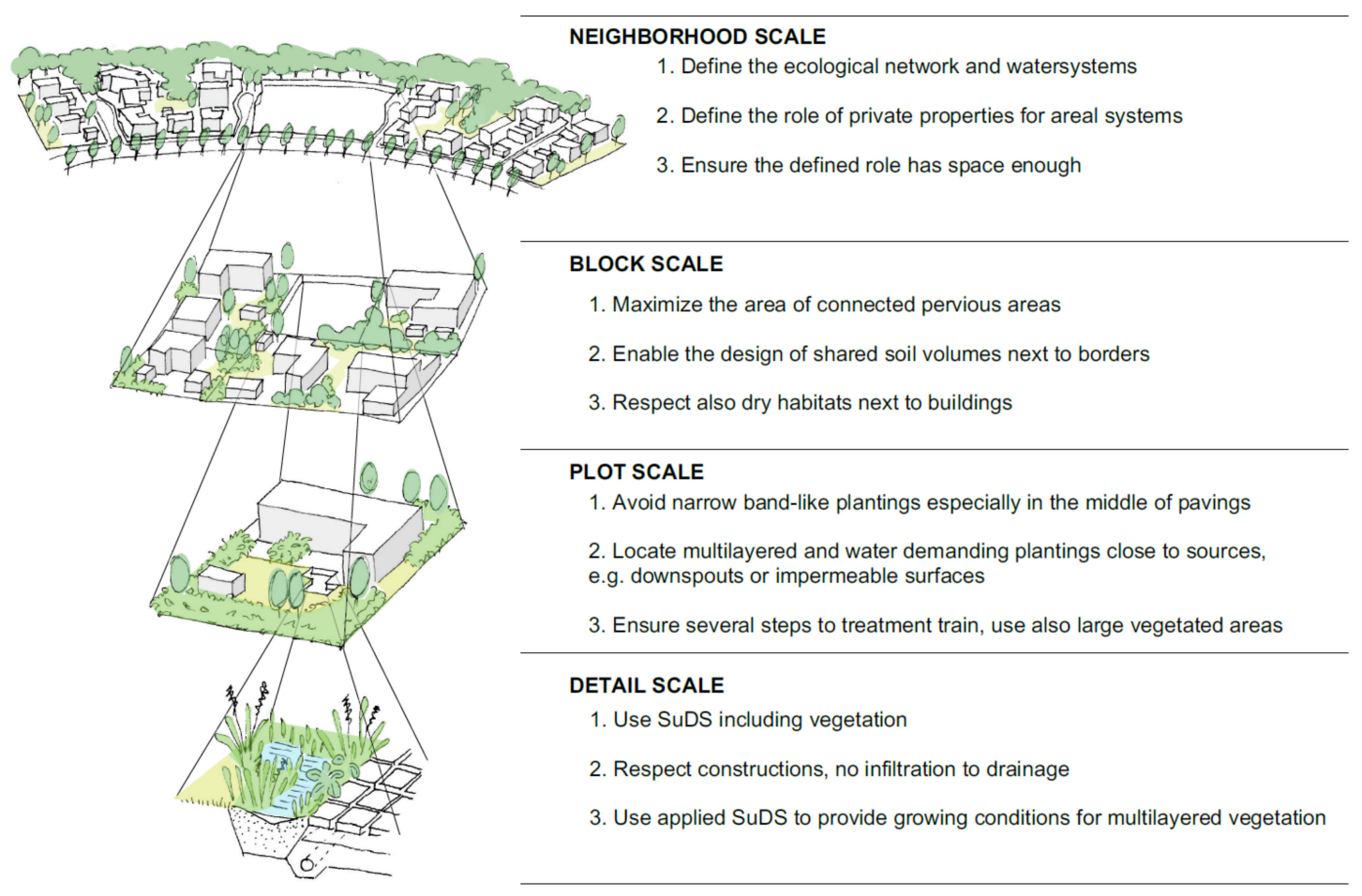

Figure 7. Proposed checklist for designers to work with scalable green infrastructure (GI) in low density housing.

In this system, soil is the interface between vegetation and water that enables water to filtrate, be retained, infiltrate, and rise due to capillary actions. In turn, vegetation absorbs the available water for its growth and releases water to the atmosphere. The decomposition of dead leaves and litter forms organic matter $(\mathrm{OM})$ that contains nutrients needed for growth, and OM improves the water-holding capacity in soil that supports the availability of water to vegetation between rain events. OM supports the living conditions of micro-organisms, thereby improving biodiversity in the soil. In addition, the development of a root system supports water infiltration.

This core system of GI does not correspond to the traditional planting design process that includes the selection of plant species, but rather, is concerned with seeking a balance between soil, vegetation, and water. This system (a) can be found in some form on all surfaces of a built environment and (b) functions in constant interaction with the ways that people use areas and manage their gardens. Based on the results of this study, this system of water, vegetation and soil was identified to be a key factor in the design of vegetation integrated stormwater management. This finding is in line with the claims that the provision of ecosystem services builds on hydrologically active surfaces [52] and vegetated surfaces [53].

The proportion of sealed surfaces and their foundations limit the soil volume that is available for the system of water, vegetation, and soil. The smaller the space left for vegetation is, the more vulnerable the GI's CS is, and there might be a need to support this system by using fertilizers or irrigation. This brings up the question of what the minimum space for a self-sustaining GI core system is. If soil is considered solely as a filter through which stormwater infiltrates, the opportunity to provide soil water for vegetation is lost. The purpose is not to drown the plants with excessive water 
but to make sure that the soil holds available water for vegetation to withstand drought between rain events.

\section{Conclusions}

Garden scale GI can be enhanced by integrating stormwater management to vegetation, and this enhanced GI at plot scale affects also block and neighbourhood scales. This integration requires garden designers to have the knowledge of the interconnected system of water, vegetation, and soil and its on-going processes in the detail scale. This knowledge is essential when designing both good growing conditions for vegetation and technical safety for buildings and constructions. This integrative designing demands balancing between proportions of green and grey, impervious and pervious surfaces, to place the areas of water demand and runoff generation in relation to each other. Furthermore, designing must consider water flows not only on surface but also in surface layer next to construction foundations. This integrative approach needs to be the aim already in the early steps of design process. The careful design of separate vegetation or water systems will not suffice on its own.

Plot scale integration of stormwater and vegetation can provide improved growing conditions that serve for the continuum of different water demanding habitat types. Furthermore, it stresses the role of plots every square meter for stormwater management, not only the set of separate SuDS. This integrative approach starts from plot scale and the set of decisions in garden designs. However, urban planners need to realize its potential in block and neighbourhood scales as the outcome may improve biodiversity potential in the whole residential area and that returns back to residents as ecosystem services.

Funding: This study was financially supported through Maiju and Yrjö Rikala's Garden Foundation.

Conflicts of Interest: The authors declare no conflict of interest. The founding sponsors had no role in the design of the study; in the collection, analyses, or interpretation of data; in the writing of the manuscript, and in the decision to publish the results.

\section{References and Notes}

1. Davies, C.; Lafortezza, R. Urban green infrastructure in Europe: Is greenspace planning and policy compliant? Land Use Policy 2017, 69, 93-101. [CrossRef]

2. Supporting the Implementation of Green Infrastructure Final Report. 2016. Available online: http://ec. europa.eu/environment/nature/ecosystems / docs/green_infrastructures/GI\%20Final\%20Report.pdf (accessed on 1 December 2018).

3. Liquete, C.; Kleeschulte, S.; Dige, G.; Maes, J.; Grizzetti, B.; Olah, B.; Zulian, G. Mapping green infrastructure based on ecosystem services and ecological networks: A Pan-European case study. Environ. Sci. Policy 2015, 54, 268-280. [CrossRef]

4. Ahern, J. Green Infrastructure for cities. The spatial dimensions. In Cities of the Future towards Integrated and Landscape Management; Novotny, V., Ed.; IWA Publications: London, UK, 2007; pp. 267-283.

5. Fletcher, T.D.; Shuster, W.; Hunt, W.F.; Ashley, R.; Butler, D.; Arthur, S.; Trowsdale, S.; Barraud, S.; Semadeni-Davies, A.; Bertrand-Krajewski, J.L.; et al. SUDS, LID, BMPs, WSUD and more-The evolution and application of terminology surrounding urban drainage. Urban Water J. 2015, 12, 525-542. [CrossRef]

6. Wright, H. Understanding green infrastructure: The development of a contested concept in England. Local Environ. 2011, 16, 1003-1019. [CrossRef]

7. Benedict, M.A.; McMahon, E.T. Green Infrastructure: Smart conservation for the 21st century. Renew. Resour. J. 2002, 20, 12-17.

8. Pitman, S.D.; Daniels, C.B.; Ely, M.E. Green infrastructure as life support: Urban nature and climate change. Trans. R. Soc. South Aust. 2015, 139, 97-112. [CrossRef]

9. Kambites, C.; Owen, S. Renewed prospects for green infrastructure planning in the UK. Plan. Pract. Res. 2006, 21, 483-496. [CrossRef]

10. Mell, I.C. Green Infrstructure: Concepts and planning. Forum eJ. 2008, 8, 69-80. 
11. Hansen, R.; Olafsson, A.S.; van der Jagt, A.P.N.; Rall, E.; Pauleit, S. Planning multifunctional green infrastructure for compact cities: What is the state of practice? Ecol. Indic. 2019, 96, 99-110. [CrossRef]

12. Koc, C.B.; Osmond, P.; Peters, A. A Green Infrastructure Typology Matrix to Support Urban Microclimate Studies. Procedia Eng. 2016, 169, 183-190. [CrossRef]

13. Tu, M.C.; Smith, P. Modeling Pollutant Buildup and Washoff Parameters for SWMM Based on Land Use in a Semiarid Urban Watershed. Water Air Soil Pollut. 2018, 229, 4. [CrossRef]

14. Tahvonen, O.; Airaksinen, M. Low-density housing in sustainable urban planning - Scaling down to private gardens by using the green infrastructure concept. Land Use Policy 2018, 75, 478-485. [CrossRef]

15. Loram, A.; Tratalos, J.; Warren, P.H.; Gaston, K.J. Urban domestic gardens (X): The extent \& structure of the resource in five major cities. Landsc. Ecol. 2007, 22, 601-615.

16. Mathieu, R.; Freeman, C.; Aryal, J. Mapping private gardens in urban areas using object-oriented techniques and very high-resolution satellite imagery. Landsc. Urban Plan. 2007, 81, 179-192. [CrossRef]

17. Dewaelheyns, V.; Rogge, E.; Gulinck, H. Putting domestic gardens on the agenda using empirical spatial data: The case of Flanders. Appl. Geogr. 2014, 50, 132-143. [CrossRef]

18. Whitford, V.; Ennos, A.R.; Handley, J.F. City form and natural process indicators for the ecological performance of urban areas and their alpplication to merseyside, uk.pdf. Landsc. Urban Plan. 2001, 57, 91-103. [CrossRef]

19. Gaston, K.J.; Warren, P.H.; Thompson, K.; Smith, R.M. Urban domestic gardens (IV): The extent of the resource and its associated features. Biodivers. Conserv. 2005, 14, 3327-3349. [CrossRef]

20. Cameron, R.W.; Blanuša, T.; Taylor, J.E.; Salisbury, A.; Halstead, A.J.; Henricot, B.; Thompson, K. The domestic garden-Its contribution to urban green infrastructure. Urban For. Urban Green. 2012, 11, $129-137$. [CrossRef]

21. Kelly, D.A. How Does Your Garden Flow? The Impact of Domestic Front Gardens on Urban Flooding. Br. J. Environ. Clim. Chang. 2016, 6, 149-158. [CrossRef]

22. Dee, C. Form and Fabric in Landscape Architecture A Visual Introduction; Spon Press: New York, NY, USA, 2001.

23. Booth, N.K.; Hiss, J.E. Residential Landscape Architecture: Design Process for the Private Residence, 6th ed.; Prentice Hall: Upper Saddle River, NJ, USA, 2012.

24. Nouri, H.; Beecham, S.; Kazemi, F.; Hassanli, A.M. A review of ET measurement techniques for estimating the water requirements of urban landscape vegetation. Urban Water J. 2013, 10, 247-259. [CrossRef]

25. Ossola, A.; Hahs, A.K.; Nash, M.A.; Livesley, S.J. Habitat Complexity Enhances Comminution and Decomposition Processes in Urban Ecosystems. Ecosystems 2016, 19, 927-941. [CrossRef]

26. Keeley, M. The green area ratio: An urban site sustainability metric. J. Environ. Plan. Manag. 2011, 54, 937-958. [CrossRef]

27. Szulczewska, B.; Giedych, R.; Borowski, J.; Kuchcik, M.; Sikorski, P.; Mazurkiewicz, A.; Stańczyk, T. How much green is needed for a vital neighbourhood? In search for empirical evidence. Land Use Policy 2014, 38, 330-345. [CrossRef]

28. Kellagher, R. The SUDS Manual; CIRIA: London, UK, 2007.

29. "CIRIA SuDS Manual 2015".

30. Charlesworth, S.; Warwick, F.; Lashford, C. Decision-making and sustainable drainage: Design and scale. Sustainability 2016, 8, 782. [CrossRef]

31. Bastien, N.; Arthur, S.; Wallis, S.; Scholz, M. The best management of SuDS treatment trains: A holistic approach. Water Sci. Technol. 2010, 61, 263-272. [CrossRef]

32. Wootton-Beard, P.C.; Xing, Y.; Durai Prabhakaran, R.T.; Robson, P.; Bosch, M.; Thornton, J.M.; Ormondroyd, G.A.; Jones, P.; Donnison, I. Review: Improving the Impact of Plant Science on Urban Planning and Design. Buildings 2016, 6, 48. [CrossRef]

33. Eskola, R.; Tahvonen, O. Hulevedet Rakennetussa Viherympäristössä; Hämeen Ammattikorkeakoulu: Hämeenlinna, Finland, 2010.

34. Brabec, E.; Schulte, S.; Richards, P.L. Impervious surfaces and water quality: A review of current literature and its implications for watershed planning. J. Plan. Lit. 2002, 16, 499-514. [CrossRef]

35. Arnold, C.L.; Gibbons, C.J. Impervious surface coverage: The emergence of a key environmental indicator. J. Am. Plan. Assoc. 1996, 62, 243-258. [CrossRef]

36. Kuusisto-Hjort, P.; Hjort, J. Land use impacts on trace metal concentrations of suburban stream sediments in the Helsinki region, Finland. Sci. Total Environ. 2013, 456-457, 222-230. [CrossRef] 
37. Yang, B.; Li, S. Green Infrastructure Design for Stormwater Runoff and Water Quality: Empirical Evidence from Large Watershed-Scale Community Developments. Water 2013, 5, 2038-2057. [CrossRef]

38. Goddard, M.A.; Dougill, A.J.; Benton, T.G. Scaling up from gardens: Biodiversity conservation in urban environments. Trends Ecol. Evol. 2010, 25, 90-98. [CrossRef] [PubMed]

39. Threlfall, C.G.; Ossola, A.; Hahs, A.K.; Williams, N.S.G.; Wilson, L.; Livesley, S.J. Variation in Vegetation Structure and Composition across Urban Green Space Types. Front. Ecol. Evol. 2016, 4, 1-12. [CrossRef]

40. Fairbrass, A.; Jones, K.; McIntosh, A.; Yao, Z.; Malki-Epshtein, L.; Bell, S. Green Infrastructure for London: A Review of the Evidence; The Engineering Exchange: London, UK, 2018.

41. Roggema, R. Research by Design: Proposition for a Methodological Approach. Urban Sci. 2016, 1, 2. [CrossRef]

42. De Jong, T.; van der Voordt, T. Criteria for scientific study and design. In Ways to Study and Research; De Jong, T., van der Voordt, T., Eds.; Delft University Press: Delft, The Netherlands, 2002; pp. 19-30.

43. Glanville, R. Research Design and Designing Research. Des. Issues 1999, 15, 80-91. [CrossRef]

44. Simon, H.A. The Sciences of the Artificial; MIT Press: Cambridge, MA, USA, 1969.

45. Tahvonen, O. Impervious coverage in Finnish single-family house plots management and creating urban green spaces. Archit. Res. Finl. 2018, 2, 180-194.

46. Harrison-Atlas, D.; Theobald, D.M.; Goldstein, J.H. A systematic review of approaches to quantify hydrologic ecosystem services to inform decision-making. Int. J. Biodivers. Sci. Ecosyst. Serv. Manag. 2016, 12, 160-171. [CrossRef]

47. Tahvonen, O. Water for Vegetation-Knowledge Base for an Integrated Approach to Sustainable Stormwatern Management in Site Scale. In In Proceedings of the Eclas 2014 Conference, Landscape: A Place for Cultivation, Porto, Portugal, 21-23 September 2014; pp. 331-333.

48. Tu, M.C.; Traver, R. Clogging impacts on distribution pipe delivery of street runoffto an infiltration bed. Water 2018, 10, 1045. [CrossRef]

49. Keeley, M. Green Roofs Incentives: Tried and True Techniques from Europe. In In Proceedings of the Second Annual Green Roof for Healthy Cities Conference, Portland, OR, USA, 2-4 June 2004.

50. Beninde, J.; Veith, M.; Hochkirch, A. Biodiversity in cities needs space: A meta-analysis of factors determining intra-urban biodiversity variation. Ecol. Lett. 2015, 18, 581-592. [CrossRef] [PubMed]

51. Mumaw, L.; Bekessy, S. Wildlife gardening for collaborative public-private biodiversity conservation. Australas. J. Environ. Manag. 2017, 24, 242-260. [CrossRef]

52. Stone, B. The City and the Coming Climate: Climate Change in the Places We Live; University of Cambridge Press:: Cambridge, MA, USA, 2012.

53. Abunnasr, Y.F. Climate Change Adaptation: A Green Infrastructure Planning Framework for Resilient Urban Regions. Ph.D. Thesis, University of Massachusetts Amherst:, Amherst, MA, USA, 2013; pp. 1-243. 